\title{
Acute Respiratory Distress and Its Risk Factors among Neonates Admitted in a Tertiary Care Center of Western Nepal
}

\author{
Adhikari I', Aryal $\mathrm{S}^{2}$, Gupta $\mathrm{V}^{3}$
}

\begin{abstract}
BACKGROUND: Neonatal period is defined as a period from birth to under 4 weeks ( $<28$ days) of age. It is a highly vulnerable time for an infant, who is completing many of the physiologic adjustments required for extra uterine existence. The term Respiratory distress (RD) is used to indicate signs \& symptoms of abnormal respiratory pattern. Methods: All neonates admitted in neonatal intensive care unit of Nepalgunj Medical College, Kohalpur with respiratory distress were included. Same number of age and sex matched controls without RD were selected. Results: The NICU based hospital incidence of RD was 9.1\% with male: female ratio 1.4:1. The most common etiology was neonatal sepsis $(51.6 \%)$, followed by hyaline membrane disease (17.8\%), TTN (12.7\%), meconium aspiration syndrome $(6 \%)$, birth asphyxia $(5.08 \%)$, tracheoesophageal fistula $(2 \%)$ and pneumothorax (2\%). Newborns with poor APGAR score requiring resuscitation were more likely to develop $R D(p=0.025)$. Newborns with birth weight $<2.5 \mathrm{~kg}$ and $>4 \mathrm{~kg}$ were 2 times likely to develop RD as compared to control group $(p<0.012)$. There was 7 times higher risk of developing MAS when a baby was born through thick MSL as compared to control group $(P<0.022)$. Inadequate ANC visit significantly increased RD in newborns $(p<0.001)$. Babies born to mother with PROM for more than 18 hours were 5.5 times likely to develop RD $(p<0.001)$ whereas those born to mother who had any source of infection were about 6 times at risk of developing respiratory distress than control group $(p=0.007)$. Conclusion: Certain measures that could be taken to reduce the number of RD are: 1 . discouraging early marriage and teenage pregnancy. 2. Increasing awareness regarding temporary and permanent contraceptive measures. 3 . Promoting education of girls. 4. Increasing coverage of ANC visit in rural areas and 5. formulating integrated plan and policies from the Government level.
\end{abstract}

Key words: Incidence, respiratory distress, riskfactors

\section{INTRODUCTION}

Neonatal period is defined as the first 28 days after birth. It is a highly vulnerable time for an infant, who is completing many of the physiologic adjustments required for extra uterine existence. The high neonatal morbidity and mortality rates attest to the fragility of life during this period; of all deaths occurring in the 1st yr of life two thirds are in the neonatal period $^{1}$. Respiratory distress (RD) constitutes the commonest cause of morbidity in newborn babies and pulmonary pathology is the most frequent autopsy findings in the neonates ${ }^{2}$.

The term Respiratory distress (RD) is often used to indicate signs \& symptoms of abnormal respiratory pattern ${ }^{1}$. A newborn with RD is characterized by tachypnoea (more than 60 breaths per min), nasal flaring, stridor, grunting, dyspnoea, wheezing, central cyanosis, chest wall retractions \& working of accessory muscles. Presence of two or more signs persisting for four hours or more suggest respiratory distress ${ }^{1,3}$. Severity of RD can be assessed by Downe's scoring system ${ }^{4}$.

1. Dr. Jyoti Adhikari

2. Dr. Sajju Aryal

3. Prof. Veena Gupta

Address for correspondence:

Dr. Jyoti Adhikari

Department of Pediatrics

Nepalgunj Medical College Teaching Hospital

Kohalpur, Banke, Nepal

Email: adhikarijyoti@yahoo.com
$\mathrm{RD}$ is one of the most common emergency problems seen in newborn responsible for $30-40 \%$ admission in neonatal period ${ }^{5}$. The importance of $R D$ in neonates can be realized from the fact that the neonates with respiratory distress are 2-4 times more likely to die than those without respiratory distress so its prevention and adequate management will decrease mortality ${ }^{6}$. Failure to readily recognize symptoms and treat the underlying cause of respiratory distress in newborn can lead to short and long-term complications, including respiratory failure and even death as short term and chronic lung disease or recurrent pneumonia as long term complication ${ }^{7,8}$. There are many identifiable maternal and neonatal risk factors causing respiratory distress which if recognized in time can give better neonatal outcome.

\section{MATERIALS AND METHODS}

A prospective case control study was carried out among newborns with respiratory distress admitted to neonatal intensive care unit (NICU) from labor room and obstretic ward of Nepalgunj Medical college Teaching Hospital, Kohalpur, Banke over the period of one year from January 2016 A.D to December 2016 A.D. Total of 118 neonates developed respiratory distress and all were included in the study. Another 118 newborns without respiratory distress were taken delivered at the same time, matched age and sex wise as a control group to determine the risk factors of respiratory distress. All newborns whose mothers were willing to participate and delivered in NGMCTH were included in the study whereas those mothers not willing to participate, delivered outside NGMCTH and neonates without respiratory 
distress whose gestational age and sex not matched were excluded from the study. Every mother was interviewed personally in Nepalese language. Details of neonates regarding age, sex, birth weight and APGAR score, maternal factors like ANC visits, history of leaking, fever were recorded in interview forms, data was processed and analyzed by using Statistical Package for Social Sciences (SPSS 19). Variables were expressed in the form of frequencies and percentage. Chi square test and Odd Ratio was computed to analyze relationship between risk factors.

\section{RESULTS}

During the study period 1306 newborns (inborn) were admitted to NICU, out of which 118 neonates developed respiratory distress giving an incidence of $9.1 \%$ and all were included in the study. Another 118 newborns were taken

\begin{tabular}{|l|c|c|}
\hline Etiology & Number(n) & \% \\
\hline Neonatal sepsis & 61 & 51.6 \\
\hline Hyaline membrane disease & 21 & 17.8 \\
\hline Transient tachypnea of newborn & 15 & 12.7 \\
\hline Meconium aspiration syndrome & 7 & 6 \\
\hline Birth asphyxia & 6 & 5.08 \\
\hline Congenital heart disease & 4 & 3.4 \\
\hline Tracheosophageal fistula & 2 & 1.62 \\
\hline Pneumothorax & 2 & 1.62 \\
\hline Total & $\mathbf{1 1 8}$ & $\mathbf{1 0 0}$ \\
\hline
\end{tabular}

Table I: Etiology of Respiratory distress in cases $(n=118)$ delivered at the same time, matched age and sex wise as a control group to determine the risk factors of respiratory distress. Out of these, 69(58.5\%) cases were male and $49(41.5 \%)$ were female giving male: female ratio of 1.4:1.

The most common etiology found in the study was neonatal sepsis (51.6\%), followed by hyaline membrane disease (17.8\%) and TTN (12.7\%). Least common causes were tracheosophageal fistula (1.62\%) and pneumothorax (1.62\%). The study showed that newborns born with poor apgar score i.e. $<5$ requiring resuscitation were more likely to develop respiratory distress which was statistically significant $(p=0.025)$.

Birth weight of newborn was divided into high risk group $(<2.5$ $\mathrm{kg}$ and $>4 \mathrm{~kg}$ ) and normal weight group (2.5-4 kg). In this study newborn who had high risk birth weight were 2 times likely to develop respiratory distress as compared to control group which was statistically significant $(p=0.012)$.

The study showed that there was 7 times higher risk of developing MAS when a baby born through thick MSL as compared to control group which was statistically significant $(P=0.022)$. The mothers who had inadequate ANC visit were likely to have babies with RD which is statistically significant. $(p<0.001)$

The study showed that babies born to mothers with PROM for more than 18 hours were 5.5 times likely to develop respiratory distress which was statistically significant $(p<0.001)$.

\begin{tabular}{|c|c|c|c|c|c|}
\hline \multirow{2}{*}{ APGAR score } & \multicolumn{2}{|c|}{ Respiratory distress } & \multirow{2}{*}{ Total n (\%) } & OR (95\% Cl) & $P$ value \\
\hline & Present(\%) & Absent (\%) & & \multirow{4}{*}{$\begin{array}{c}0.209 \\
(0.044-0.988)\end{array}$} & \multirow{4}{*}{0.025} \\
\hline$>5$ & 109(92.37) & $116(98.30)$ & $221(93.64)$ & & \\
\hline$<5$ & $9(7.63)$ & $2(1.7)$ & $15(6.35)$ & & \\
\hline Total & $118(100)$ & $118(100)$ & $236(100)$ & & \\
\hline
\end{tabular}

Table II: Association of RD with APGAR score

\begin{tabular}{|c|c|c|c|c|c|}
\hline \multirow{2}{*}{$\begin{array}{c}\text { Birth weight } \\
\text { (kg) }\end{array}$} & \multicolumn{2}{|c|}{ Respiratory distress } & \multirow{2}{*}{ Total n (\%) } & OR $(95 \% \mathrm{Cl})$ & $P$ value \\
\hline & Present(\%) & Absent (\%) & & \multirow{4}{*}{$\begin{array}{c}2.035 \\
(1.200-3.452)\end{array}$} & \multirow{4}{*}{0.012} \\
\hline$<2.5>4$ & $58(49.15)$ & $38(32.20)$ & $96(40.67)$ & & \\
\hline $2.5-4$ & $60(50.85)$ & $80(69.80)$ & $140(59.33)$ & & \\
\hline Total & $118(100)$ & $118(100)$ & $236(100)$ & & \\
\hline
\end{tabular}

Table III: Association of birth weight with RD

\begin{tabular}{|c|c|c|c|c|c|}
\hline \multirow{2}{*}{ MSL } & \multicolumn{2}{|c|}{ Respiratory distress } & \multirow{2}{*}{ Total n (\%) } & OR (95\% Cl) & P value \\
\hline & Present(\%) & Absent (\%) & & \multirow{3}{*}{$\begin{array}{c}7.37 \\
(60.93-0.893)\end{array}$} & \multirow{3}{*}{0.022} \\
\hline Present & $7(5.93)$ & $1(0.84)$ & $8(3.38)$ & & \\
\hline Absent & $111(94.06)$ & 117 (99.1) & $228(96.61)$ & & \\
\hline
\end{tabular}

Table IV: Association of RD with Thick meconium stained liquor 
Adhikari et al.: Acute Respiratory Distress and Its Risk Factors among Neonates Admitted in a Tertiary Care Center of Western Nepal

\begin{tabular}{|c|c|c|c|c|c|}
\hline \multirow{2}{*}{ ANC visit } & \multicolumn{2}{|c|}{ Respiratory distress } & \multirow{2}{*}{ Total n (\%) } & OR $(95 \% \mathrm{Cl})$ & $P$ value \\
\hline & Present(\%) & Absent (\%) & & \multirow{3}{*}{$\begin{array}{c}0.232 \\
(0.105-0.532)\end{array}$} & \multirow{3}{*}{$<0.001$} \\
\hline Adequate & $87(73.72)$ & $109(92.37)$ & $196(83.05)$ & & \\
\hline Inadequate & $31(26.27)$ & $9(7.6)$ & 40 (16.94) & & \\
\hline Total & $118(100)$ & $118(100)$ & $236(100)$ & & \\
\hline
\end{tabular}

Table V: Association of RD with maternal ANC visits

\begin{tabular}{|c|c|c|c|c|c|}
\hline \multirow{2}{*}{$\begin{array}{l}\text { PROM } \\
>18 \text { hours }\end{array}$} & \multicolumn{2}{|c|}{ Respiratory distress } & \multirow{2}{*}{ Total n (\%) } & OR $(95 \% \mathrm{Cl})$ & $P$ value \\
\hline & Present(\%) & Absent (\%) & & \multirow{3}{*}{$\begin{array}{c}5.532 \\
(12.10-2.52)\end{array}$} & \multirow{3}{*}{$<0.001$} \\
\hline Present & $37(31.35)$ & $9(7.6)$ & $46(19.4)$ & & \\
\hline Absent & $81(68.6)$ & $109(92.4)$ & $190(80.5)$ & & \\
\hline Total & $118(100)$ & $118(100)$ & $236(100)$ & & \\
\hline
\end{tabular}

Table VI: Association of RD with PROM for more than 18 hours

\begin{tabular}{|c|l|c|c|c|c|}
\hline \multirow{2}{*}{$\begin{array}{c}\text { Maternal } \\
\text { infection }\end{array}$} & \multicolumn{2}{|c|}{ Respiratory distress } & \multirow{2}{*}{ Total $\mathbf{n}(\%)$} & OR (95\% Cl) & P value \\
\cline { 2 - 3 } & Present(\%) & Absent (\%) & & \multirow{2}{*}{5.963} & \multirow{2}{*}{0.007} \\
\hline Present & $11(9.3)$ & $2(1.6)$ & $13(5.5)$ & \\
\hline Absent & $107(90.6)$ & $116(98.3)$ & $223(94.5)$ & \\
\hline Total & $118(100)$ & $118(100)$ & $236(100)$ & & \\
\hline
\end{tabular}

Table VII: Association of RD with maternal infection

Maternal history of infection was taken as fever, foul smelling vaginal discharge or symptoms suggestive of urinary tract infection. This study showed that newborns born to mothers who had any source of infection were about 6 times at risk to develop respiratory distress than compared to control group which was statistically significant (0.007).

\section{DISCUSSION}

The importance of respiratory distress in neonates can be realized from the fact that the neonates with respiratory distress are two to four times more likely to die than those without respiratory distress ${ }^{6}$. Knowledge of respiratory distress is important so as to plan and provide the basic facilities for sick and low birth weight newborns ${ }^{9}$. In our study respiratory distress constituted $9.1 \%$ of all inborn cases admitted in Neonatal Intensive Care Unit during study period. This is similar to other studies done by Kumar et $\mathrm{al}^{10}$ and Lui et al ${ }^{11}$ where the incidence was reported as $6.7 \%$ and $6.8 \%$ respectively.

Out of 118 newborns, 69 (58.5\%) were male 49 (41.5\%) female with male: female ratio $1.4: 1$ suggesting more male preponderance which is similar with other studies ${ }^{12,13,14}$. This can be explained by the fact that due to the sex-limited biochemical process i.e. male fetuses are exposed to high level of androgens and Mullerian Inhibiting Substance (MIS) which inhibit lung development and thereby leading to relative immaturity of male fetal lungs as compared to female fetal lungs in last two months of pregnancy ${ }^{15}$.
The most common cause of respiratory distress in our study was neonatal sepsis (51.6\%) followed by hyaline membrane disease $(17.8 \%)$, transient tachypnea of newborn $(12.7 \%)$, meconium aspiration syndrome (6\%), and birth asphyxia (5\%). Other less common causes were congenital heart disease (3.4\%), tracheosophageal fistula (1.62\%) and pneumothorax (1.62\%). The most common cause of acute respiratory disorder as reported by Ali Z in his study was pulmonary infection (39\%) followed by hyaline membrane disease (29\%) and birth asphyxia $(10.9 \%)^{12}$. Another study from India conducted by Mathur et al reported that $29 \%$ of all admissions to neonatal unit were due to respiratory distress out of which pneumonia $(68.6 \%)$ was the most common cause of respiratory distress ${ }^{16}$. Such a high incidence of neonatal sepsis in our study was due to high number of mothers with some focus of infection and premature rupture of membrane for more than 18 hours which are considered as the strong risk factors of neonatal sepsis.

The study showed that newborns born with poor APGAR score were statistically more likely to develop respiratory distress which is similar to other study conducted by Kumar et al. ${ }^{10}$ About $50 \%$ of newborns with respiratory distress had high risk birth weight i.e. $<2.5 \mathrm{~kg},>4 \mathrm{~kg}$. It was shown that newborns with high risk birth weight were 2 times more likely to develop $\mathrm{RD}$ as compared to control group which is similar to other studies ${ }^{12,17,18}$. It could be because of the fact that low birth weight babies could not initiate and sustain breathing soon after delivery, so more prone for RD and respiratory failure ${ }^{19}$. 
$6 \%$ of newborn had MAS and all had thick meconium stained liquor and all were full term babies. Zazzou et al. reported $100 \%$ of MAS developed in newborns born to meconium stained liquor $^{14}$. There are various studies reporting MAS who were delivered through meconium stained liquor ${ }^{20,21,22}$. It is because of the fact that meconium when aspirated into tracheobronchial tree causes airway obstruction, chemical pneumonitis, surfactant dysfunction and persistent pulmonary hypertension (PPHN) causing RD ${ }^{15}$.

The mothers who had inadequate ANC visit were more likely to have babies with RD which is similar to other study ${ }^{17}$. It could be due to geographical restraint, financial issues, lack of awareness, family burden and lack of health facilities that most women don't get enough care during pregnancy.

In this study babies born to mothers with PROM $>18$ hours were 5.5 times more likely to develop RD ( $p$ value $<0.001$ ). Similar result was given by Merenstein G B et al and Zaazou et $\mathrm{al}^{14,23}$. It could be because of the fact that PROM leads to more chances of infection, prematurity, lung hypoplasia and fetal distress all being potential causes of neonatal RD ${ }^{15,24}$.

In the present study newborns born to mother with any source of infection (UTI, fever, chorioamnionitis) were about 6 times more likely to develop RD as compared to control group which was statistically significant ( $p$ value 0.007 ). Similar result was given by Chan $\mathrm{CJ}_{\text {et }} \mathrm{al}^{25}$.

\section{CONCLUSION}

Respiratory distress is one of the most common cause of morbidity and mortality in neonates. So to decrease the incidence of respiratory distress following measures should be taken at the Government level viz: early marriage and teenage pregnancies to be discouraged, knowledge about use of temporary and permanent contraceptive measure should be given, education level of every girl should be promoted, coverage of ANC visits should be increased helping early diagnosis as well as treatment of maternal infection and health care facilities of tertiary level should be provided in rural areas.

\section{ACKNOWLEDGEMENTS}

My sincere thanks to Lord Buddha Educational Academy, NGMCTH, Kohalpur administration, Principal's office and pediatric department for their valuable contribution.

\section{REFERENCES}

1. Sarnaik AP, Clark JA. Respiratory Distress and Failure. In Kliegman R M, Stanton B F, St.Geme J W, Schor N F editors. $19^{\text {th }}$ ed. Nelson Textbook of Paediatrics. Philadelphia Elsevier .2011;65(I), p314532.

2. Paul VK, Deorani AK, Agrawal R et al.Newborn Infants. In Ghai OP, Paul VK, Bagga A editors. $7^{\text {th }}$ ed. CBS publishers \& distributors Pvt Ltd, New Delhi 2009;142.

3. Dutta AK. Respiratory Distress in Newborn. Advances in Paediatrics. Sachdeva A, Dutta Ak, Jain MP. $2^{\text {nd }}$ edition, Pedicon, Gurgaon 2012;11(I),p83.
4. Wood DW, Downes JJ, Lecks HI. A clinical scoring system for the diagnosis of respiratory distress: preliminary report on newborn. Am J Dis Child. 1972;123:227-8.

5. NNF Recommended Basic Perinatal-Neonatal Nomenclature.In: DK Guha, editors. Neonatology- Principles and Practice.1st ed. New Delhi : Jaypee Brothers 1998: 131-2.

6. Mishra PK. Respiratory distress in newborn. Indian J Pediatr 1987; 24:77-80.

7. Bhat $R$, Vidyasagar $D$ Delivery room management of meconiumstained infant. Clin Perinatol. 2012;39(4):817-31

8. Gouyon JB, Ribakovsky C, Ferdynus $C$ et al. Burgundy Perinatal Network. Severe respiratory disorders in term neonates. Paediatr Perinat Epidemiol.2008;22(1):22-30

9. Khatua S.P., Gangwal A., Pathodi PKR.The incidence and etiology of respiratory distress in newborn. Indian Pediatr 1979;16:11216

10. Kumar A, Bhatt BV. Epidemiology of Respiratory Distress of Newborns. Indian J Pediatr 1996;63:93-8.

11. Lui WF, Harrington T. Delivery risk factors for meconium aspiration syndrome. Am J Perinatol. 2002;19(7):67-78

12. Ali Z. Acute respiratory disorders in the newborn at the Mount Hope Women's Hospital, Trinidad. West Indian Med J 2003;52(1)23-6

13. Hameed N N, Al Janabi M K, Al-Reda Y R. Respiratory Distress in Full Term Newborns. The Iraqui Postgraduate Medical Journal 2007;6(3);233-9

14. Zaazou H M, Kamal M M, Ali M R et al. Descriptive study of cases of Respiratory Distress in NICU in Ahmed Maher Teaching Hospital. Med J Cairo Univ 2011;79(1):441-8

15. Avery ME, Gatewood OB, Brumly G. Transient tachypnea of the newborn. Am J Dis Child. 1966;111:380

16. Mathur N B, Garg K, Kumar S. Respiratory distress in neonates with special reference to pneumonia. Indian Pediatrics 2002;39:529-37.

17. Hintz S R, Van Meurs K.P., Perritt R, et al. Neurodevelopmental Outcomes of Premature Infants with Severe Respiratory Failure Enrolied in a Randomized Controlled Trial of Inhaled Nitric Oxide. Journal of Pediatrics:2007;151:1-3.

18. Bhakoo O N, Naran A, Kumar P et al. Spectrum of respiratory distress in very low birth weight neonates. Indian J Pediatr 2000;67(11):803-4

19. Fanaroff AA, Stoll BJ, Wright LL,et al. Trends in Neonatal Morbidity and Mortality for Very Low Birth Weight Infants. American Journal of Obstetrics and Gynecology.2007;147:1-8

20. Cleary GM, Wiswell TE. Meconium-stained amniotic fluid and the meconium aspiration syndrome, an update. Pediatr Clin North Am 1998;45:511-29 2.

21. Rossi EM, Philipson EH, William TG et al. Meconium aspiration syndrome: intrapartum and neonatal attributes. Am J Obstet Gynecol 1989;161:1106-10.

22. Chaturvedi P, Yadav B, Bharambe MS. Delivery room management of neonates born through meconium stained amniotic fluid. Indian Pediatr 2000;37:1251-5.

23. Merenstein G B, Weisman L E. Premature rupture of the mambranes: neonatal consequences. Semin Perinatol 1996;20(5):375-80

24. Williams $\mathrm{O}$, Hutching $\mathrm{G}$, Hubinont $\mathrm{C}$ et al. Pulmonary effects of prolonged oligohydramnios following mid-trimester rupture of the membranes- antenatal and post natal management. Neonatology 2012;101(2):83-90

25. Chan C J, Lee A C, Bacqui A H, Tan J, Black R E. Risk of Early-onset Neonatal Infection with Maternal Infection or Colonization : a Global Systematic review and Meta-analysis.PLoS Med:2013;10(8):1-7 